to show the type of case, which clinically sees/bined with enderness at Mclsurney's point, the an exact counterpart with that in which ten- diagnosis becomes more certain. Its alsence does derness was present.

Miss K. H. Day before abdominal pain centering on the right. No increase in pulse-rate or temperature. MelBurney's point tender. No tenderness elsewhere. Operation ten days later. Appendix injected and full, stricture near base.

Mrs. C. Two attacks appendicitis, last one three weeks previous. No tenderness anywhere on examination. Appendix found with adhesions to its mesentery.

Mrs. S. Recurring attacks of pain, localizing on right. Slightly tender mass in region of appendix. No other tenderness. Operation showed mass to be omentum and intestines adherent to appendix. Pathological diagnosis: "Chronic appendicitis."

Although no series of cases was examined to determine the presence or absence of tenderness at Morris's point in conditions other than ap pendicitis, it is well to mention a case of tuberculosis of the kidney in which tenderness was present over Morris's point. In cases of chronic appendicitis, therefore, tenderness over Morris's point seems to be fairly constant though not always present. Since the tenderness at the point in question is due to a tender lymph gland, which has drained the region of the appendix, there is nothing absolutely diagnostic in its presence. Inasmuch as appendicitis is by far the most common condition of those occurring in the right iliac fossa, tenderness over Morris's point alone is very suggestive and when combined with tenderness over McBurney's point points almost surely to the appendix as the diseased organ. Its presence is not, however, an absolute proof of appendicitis.

The pelvic conditions operated upon have been so complex in the few cases recorded that it is not proper to tabulate them. 'They include acute processes starting up in chronically inflamed tubes, extra-uterine pregnancies alone and combined with chronic salpingitis and chronic appendicitis. The cases have been too coinplex to warrant any conclusions.

In all the cases (six) of gall-bladder surgery there was no tenderness helow the umbilicus. The series includes gall stones, cancer, inspissated bile, adhesions from gall bladder and liver.

\title{
CONCLUSIONS.
}

The abdominal lymphatic glands, becoming secondarily inflamed, cause tender areas. The area found tender on examination is somewhat of a guide to the organ primarily infected, and, therefore, in certain cases may be an aid in differential diagnosis.

In acute appendicitis tenderness at Morris's point is of less inportance than the symptoms caused by the appendix itself.

In chronic appendicitis tenderness at Morris's point may be of distinct diagnostic value. Tenderness at this point, even though the only physical sign, makes the diagnosis of appendicitis by the rule of chance probable; when comnot rule out appendicitis, and it may occur in other conditions.

The point has by no means the importance given to it by Dr. Morris.

\section{Clinital פDepartment.}

EARLY CERVICAL LYMPH NOHE JNLARGISMENT, THE SOLE SIGN OF CARCINOMA OF THE ESOPHAGUS. REPOIRT OF A CASE.

\footnotetext{
IX O. W. H. MTTCHeLl, M.D., ColUmBia, Mo.,
}

Pathological Laboratory, University of Missouri.

THe following report is made, not because of its being such a rare condition, but for the reason that it may possibly be of benefit to the priatitioner or surgeon who has never seen this concition or who has forgotten, in diagnosing enlargements of the cervical lymph nodes.

Patient, T. C. T., on Sept. 24, 1907, was admitted to the hospital and gave the following history: Age thirty-eight, American, farmer. Father and mother dead. Thinks father died of abscess of the liver at fifty years. Mother died at the age of fifty-five years; was sick a week or ten days; the cause of death was given as inflammation of the bowcls. Patient has four brothers and one sister living, all in good health. Some brothers and sisters died in infancy. One uncle dead from tuberculosis. Patient has had usual diseases of childhood. Said he had scrofula when a child but no glands suppurated. He has had stomach trouble for years. Last year patient had what the doctors called malarial fever. He was free from it at times but has been "no account," as the patient expresses himself, since then. Has been losing flesh, but his appetite remains good.

Examination. - Patient has good color, no cachexia, and on inspection appears normal except has marked nodular cnlargements on left side of neck along the sterno-mastoid muscle and some nodular enlargement on the right side. Skin freely movable. Patient first noticed enlargements on left side about May 1. Says enlargements on the right side have diminished. Patient complains of pain in the nodules, which rarliates to the top of his head. No sores or scales on his face or neck, but the skin over the tumor masses is hyperemic. Nothing was found on inspection of the mouth, nose or throat. Patient remained in the hospital four days, temperature ranging from normal to $99^{\circ}$. A diagnosis of cervical adenitis was made. He was unimproved when discharged.

The patient again made application for admission to the hospital on Dec. 4, 1907. Patient gave same history except that when he swallows, a lump scems to come back up in his esophagus.

Physical examination. - Throat and nose negative. Lungs. - Vocal fremitus normal. Percussion note on right upper back duller than on left. Remaining portion of back normal. On moderate or deep inspiration, a fairly large number of moist râles. Left upper back a number of fine râles. Front clear.

Heart. - Slight systolic murmur, percussion normal. Blood. - White, 8,000.

Urine examination. - Dark straw color. Specific gravity, 1,020, acid, trace of albumin, few granular casts and epithelial cells.

Temperature ranges from normal to 100 .

Patient complains of pain in the nodular enlargement 
and of headache. 'The nodules have a springy feel, as though pus were present in the deeper portions. The nodules are considerably larger than they were when patient was in the hospital in september.

Bacteriological report. - After a half hour's search one tuberele bacillus was found in the sputum.

A diacrnosis was made by exelusion. The diseases taken into consideration were the following: Tubereulosis, syphilis, Hodgkin's disease, carcinoma or sarcoma.

'Tuberculesis. - For the support of this the following was foumd:

1. Slow growith of the nodules. 2. History of scrofula. 3. Râles and dulled note on auscultation and percussion. 4. Inaly temperature, higher in the afternoon. 5. Gradual loss of flesh and weakness.

Finding of one tubercle bacillus in the sputum. 7 . l'atient's statement of decrease in size of nodules.

Syphilis. - Patient gave no history of infection nor other signs or symptoms of syphilis.

Hodgkin's discasc. - This discase was taken into consideration because of the localized enlargement of the lymph nodes but was discarded because of the inflammatory condition and lack of hyperplasia of lymph tissue elsewhere.

Carcinoma. - As there was no history of any sore or sealy conditions on the face or any other place on the skin or in the mouth, nose or throat, nor history of any marked involvement of the esophagus or stomach, carcinoma was dismissed. Lymphosarcoma was considered but was dismissed because of the many inflammatory signs and numerous signs and symptoms of tuberculosis.

Diagnosis. - Tuberculous adenitis. On Dec. 4, the patient was anesthetized and the following operation performed: An incision about five inches in length was made over the posterior border of the sternomastoid muscle and the skin and fascia divided. A large nodule presented which was removed by dry dissection. Other nodules that were adherent and encapsulated were removed through this incision. A very large nodule was removed through an incision parallel to the first and anterior to it in front of the sternomastoid. The incisions were closed; small iodoform gauze drains were inserted at the lower angles of the wounds.

Pathological cxamination. - Report from Dr. W. McN. Miller. Several nodular masses varying in size from a pea to a hen's egg, quite firm and homogeneous throughout, except the largest which shows slight nccrosis in the center. Microscopical sections from several of the nodular masses were taken and each shows typical carcinomatous structure.

Pathological diagnosis. - Carcinoma of lymph nodes metastatic, most probably from the esophagus.

The patient was dismissed from the hospital Dec. 17, 1907, improved as to pain and local symptoms; but the wound was not healed and general condition was no better. After leaving the hospital the patient developed $a$ cachexia and in about two and $a$ half months began to vomit blood and have difficulty in swallowing. Other nodules developed in the cervical region and on the right side of the chest about the level of the tenth rib. Pain in the region of the liver. From then until Aug. 11, 1908, the time of death, the patient spent most of his time in bed. Unfortunately a necropsy was not held, but the later symptoms plainly show the primary carcinoma to have its origin in the esophagus, or possibly the stomach.

In order to make the above case clearer to the reader, I quote the following two cases from Kaufmann:" "In many cases the cervical lymph

ILehrbuch der speziellen pathologischen Anatomie, dritte Aufage, Berlin, 1904, 8. 365 . norles and the connective tissue of the neck are cnormously infiltrated with eancer. it is of diagnostic importance that cancerous lympla node infiltration, which rapidly extends 1,0 surrounding soft parts, mily leat to the severest stenosis of the superior portion of the esophangus, even long before any manifestation of stenosis ativiluatahle to the tumor itself may be observed. 'l'wo examples suffice to illustrate:

" Roluust man of fifty years, four months before observed a nodule on the right side of neck which rapidly increased in size. Fix wecks thereafter a huge tumor which, on both sides, extended from the angles of the jaw to the clavicles. Hoarseness. light weeks thereafter death with symptoms of infection. Necropsy: carcinoma of the esophaigus in the middle portion, $4 \mathrm{~cm}$. in extent, without stenosis; numerous perforations into the bronchi; yenetration of both jugulars by lymph nodes; no pulnionary metastases; numerous metastases in the serosa peritorei; growth of tumor about both recurrent laryngeal nerves. Death from edema of the glottis."

"Of greater interest is the second case. A young woman of twenty-one years. A tumor the size of the fist on the left side of the neck, adherent to the vesscls. Operation: Extirpation of tumor with vessels and vagus. Microscopic examination: carcinoma. liirst at the necropsy was observed as primary tumor a macroscopically scarcely observable, quite flat, ulecrating carcinoma surrounded by a lo! wall, in the uppermost part of the esophagus. Microscopical: clearly corneous cancer. This case is also of interest because of the youthful age."

\section{CONCLUSIONS.}

From the case reprorted and the cases citerl, one should remember:

That any enlargement of the cervical lymph nodes in the adult should be regarded with suspicion as to malignant tumors. That metastases may prove to be the more malignant. 'That the primary carcinoma may not give signs or symptoms until late in its course.

'That the primary growth may never give signs or symptoms and be discovered only at the necropsy.

One should be impressed with the importance of routine patholugical exanination.

\section{OQRedical Brogregs.}

\section{PROGRESS IN THE THLOIRY ANI PRACTICE OF MEDICINE.}

Diseases of the Heart.

DY FRANCLB W. PALYREY, M.D., HOBTON, MABS.

(Concluded from No. 20, p. 870.)

\section{ARRHYTHMIAS AND ALLISD DISORDIERS OF FUNCTION.}

THw subjects covered in these studies are numerous and varied, but in general the chief attention has been devoted to the muscular activities of the heart. 'The valvular disorders have long 